\title{
First Maxillary Molar Position Alteration in Class II Division 1 Malocclusion Treatment with Maxillary Premolar Extraction
}

\author{
Elih Sayuti'1, Bergman Thahar ${ }^{1}$, Eky S. Soeria Soemantri'1, Hermawan Nagar Rasyid ${ }^{2}$ \\ ${ }^{1}$ Orthodontic Department, Faculty of Dentistry, Padjadjaran University, Bandung, Indonesia \\ ${ }^{2}$ Orthopedic Department, Faculty of Medicine, Padjadjaran University, Bandung, Indonesia \\ Email: elihortho@yahoo.co.id
}

How to cite this paper: Sayuti, E., Thahar, B., Soemantri, E.S.S. and Rasyid, H.N. (2016) First Maxillary Molar Position Alteration in Class II Division 1 Malocclusion Treatment with Maxillary Premolar Extraction. Open Access Library Journal, 3: e2936. http://dx.doi.org/10.4236/oalib.1102936

Received: August 13, 2016

Accepted: September 17, 2016

Published: September 20, 2016

Copyright $\odot 2016$ by authors and Open Access Library Inc.

This work is licensed under the Creative Commons Attribution International

License (CC BY 4.0).

http://creativecommons.org/licenses/by/4.0/

\section{(c) (i) Open Access}

\begin{abstract}
Treatment of Class II division 1 malocclusion mostly required two maxillary first premolars in order to provide spaces for maxillary anterior teeth retraction. Anterior teeth retraction may cause loss of anchorage. This study aimed at evaluating the effects of anterior teeth retraction towards first maxillary molar loss of anchorage. It was conducted by observing any mesial drifting of first maxillary molar occurred in patients with Class II division 1 malocclusion undergoing treatment with two first maxillary premolar extractions. Material consists of 25 cephalometric films of patients prior to and after orthodontic treatment using Edgewise technique. Cephalometric measurement conducted included S vertical-M1 and FHP-M1. Statistic test used was pairing $\mathrm{T}$-test, showing that $\mathrm{p}<0.05$ for paired data showed non-significant alteration in S vertical-M1 and FHP-M1 measurement prior to and after treatment. It can be concluded that mesial drifting of maxillary first molars did not occur in orthodontic treatment for Class II division 1.
\end{abstract}

\section{Subject Areas}

Dentistry

\section{Keywords}

Anchorage Loss, Mesial Drift, Anterior Retraction, Class II Division 1 Malocclusion

\section{Introduction}

Etiology of Class II division 1 malocclusion was classified into dental and skeletal abnormalities characterized by Class II molar relationship, first maxillary molar contact 
that was mesial to buccal groove of the first mandibular molar, ANB angle exceeded $4^{\circ}$, protruded anterior maxillary teeth, great overjet, deep palatal height, convex face profile, and lips incompetent. Treatment of Class II division 1 malocclusion in patients over the age of growth and development is a compromising treatment and orthognathic surgery in severe cases. Compromising treatment is an orthodontic treatment correcting dentoalveolar structure without correcting skeletal abnormality [1]. Specific characteristic of patients with Class II division 1 malocclusion was protruded incisive and convex profile. In order to correct the problem, maxillary premolars were extracted to improve crowding, provide space for anterior teeth retraction, so that large overjet may be corrected [1]. Anchorage had to be considered well to prevent anchorage loss. Anchorage consists of minimal anchorage, moderate anchorage, and maximum anchorage, used depending on the necessity [2]. Generally, in order to correct large overjet, maximum anchorage was required by involving second molar as anchorage, using palatal bar or extraoral anchorage using head gear [1]-[3].

In class II division 1, first molars were often tilted to mesial and so called Loss of anchorage or anchorage loss. Mesially drifted molar or mesially inclined first molar crown towards the space provided for anterior teeth retraction indicated anchorage loss. It may cause undesirable treatment result such as vertical dimension alteration which cause temporomandibular joint disorder. However, Proffit states that there was no sufficient data to support the claim that maxillary premolar extraction caused Temporo Mandibular Disorder. But Proffit states that no sufficient data to support the claim that the extraction of the maxillary premolar may cause Temporo Mandibular Disorder [1]. This substantial matter provoked writers to obtain data whether loss of anchorage and, if so, the distance of first molar mesial drifting occurred in Class II division 1 malocclusion treatment with first maxillary premolar extractions.

\section{Methods}

The Samples were taken from all patients with Class II division I, which had been treated at the Orthodontic Postgraduate Programme Clinic, Orthodontics Faculty of Dentistry University of Padjadjaran in 2001 until 2013. Obtained samples as many as 25 lateral cephalometry $\mathrm{x}$-rays prior to and after treatment were selected with criteria of: 1 ) Patients were Malayu Deutro; 2) were aged 15 years old or more; 3) both male and female patients were included; 4) patients documents including medical record, patient status, cephalometry lateral prior to and after treatment $\mathrm{x}$-rays were all recorded and stored thoroughly; 5) malocclusion was classified as Class II division 1;6) they have severe anteroposterior (ANB $>4^{\circ}$ ); 7) received compromised treatment using edgewise technique with two first maxillary premolar extraction; 8) treatment did not include functional device or extra oral anchorage. All subjects were treated by using standard edgewise appliance.

Cephalometric tracing was conducted manually on transparent acetate paper initiated with intraexaminer calibration. Reference points for cephalometric measurement included: Nasion (N), Sella tursica (S), Menton (Me), Gonion (Go), Gnation 
(Gn), Anterior Spina nasalis (ANS), Posterior Nasal Spine (PNS). Lines and planes measured included: Palatal plane (ANS-PNS), Frankfurt plane (superior point on the porion-inferior point on the orbitale) and occlusal plane (Figure 1).

The following parameters were used in this study in order to measure maxillary first molar drifting:

1) SNA

2) $\mathrm{SNB}$

3) $\mathrm{ANB}$

4) Mandibular plane

5) $S$ vertical-U6 (Perpendicular distance from $S$ vertical to the mesial convex point of the maxillary first molar)

6) FH-U6 (perpendicular distance from FH plane to mesiobuccal cups tip of the maxillary first)

The cephalometric measurents used in this study are discribed in Table 1 . Figure 1 shows the location of the landmark and other measurements on a tracing. A coordinate system withthe $\mathrm{FH}$ plane and a perpendicular line through sella (S vertical) was used for measuring maxillary molar position (Figure 2).

\section{Statistical Analysis}

Evaluation of first maxillary molar position alteration in Class II Division 1 Malocclusion treatment with maxillary premolar extraction, performed statistical tests. The differences between before and after treatment were determined with $t$ test. $\mathrm{p}$ values less than 0.05 were considered significant.

\section{Result}

All patients were dentally and skeletally Class II. The assesment of the skeletal relationship was based on the patient's pretreatment SNA angle, SNB angle and ANB angle. The anteroposterior position of point A relative normal to the anterior cranial base. Its mean value $83.34^{\circ}$, indicates a normal relationship between maxilla and anterior cranial. Average of SNB is $77.60^{\circ}$, its less than $78^{\circ}$, this angle defines the mandible is retrognathic. and the subject have a great ANB (5.80), its mean Class II malocclusion

Table 1. Definition of cephalometric measurement [4] [5].

\begin{tabular}{|c|c|c|}
\hline No & Measurement & Definition \\
\hline 1 & SNA & The anteroposterior position of point A relative to the anterior cranial base. \\
\hline 2 & SNB & The anteroposterior position of point B relative to the anterior cranial base. \\
\hline 3 & $\mathrm{ANB}$ & $\begin{array}{l}\text { The difference between the SNA and SNB angles, and difine the mutual } \\
\text { relationship, in sagital plane, of the maxillary and mandibular bases. }\end{array}$ \\
\hline 4 & $\begin{array}{l}\text { Mandibular } \\
\text { plane angle }\end{array}$ & Angle formed by intersection of menton-gonion and orbita pororion lines \\
\hline 5 & S vertical-U6 & $\begin{array}{l}\text { Perpendicular distance from S vertical to the mesial convex point of the } \\
\text { maxillary first molar }\end{array}$ \\
\hline 6 & FH-U6 & Distance from FH plane to mesiobuccal cups tip of the maxillary first \\
\hline
\end{tabular}




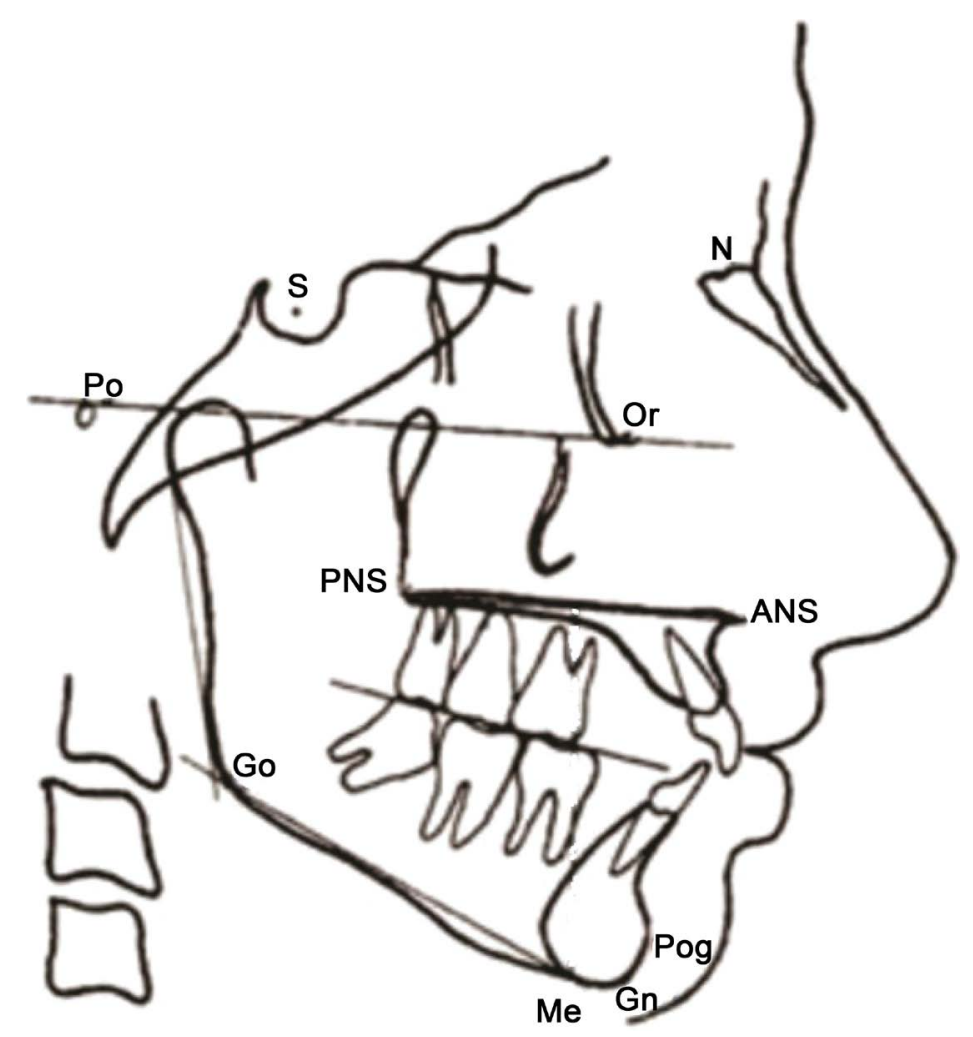

Figure 1. Lateral cephalometric landmark.

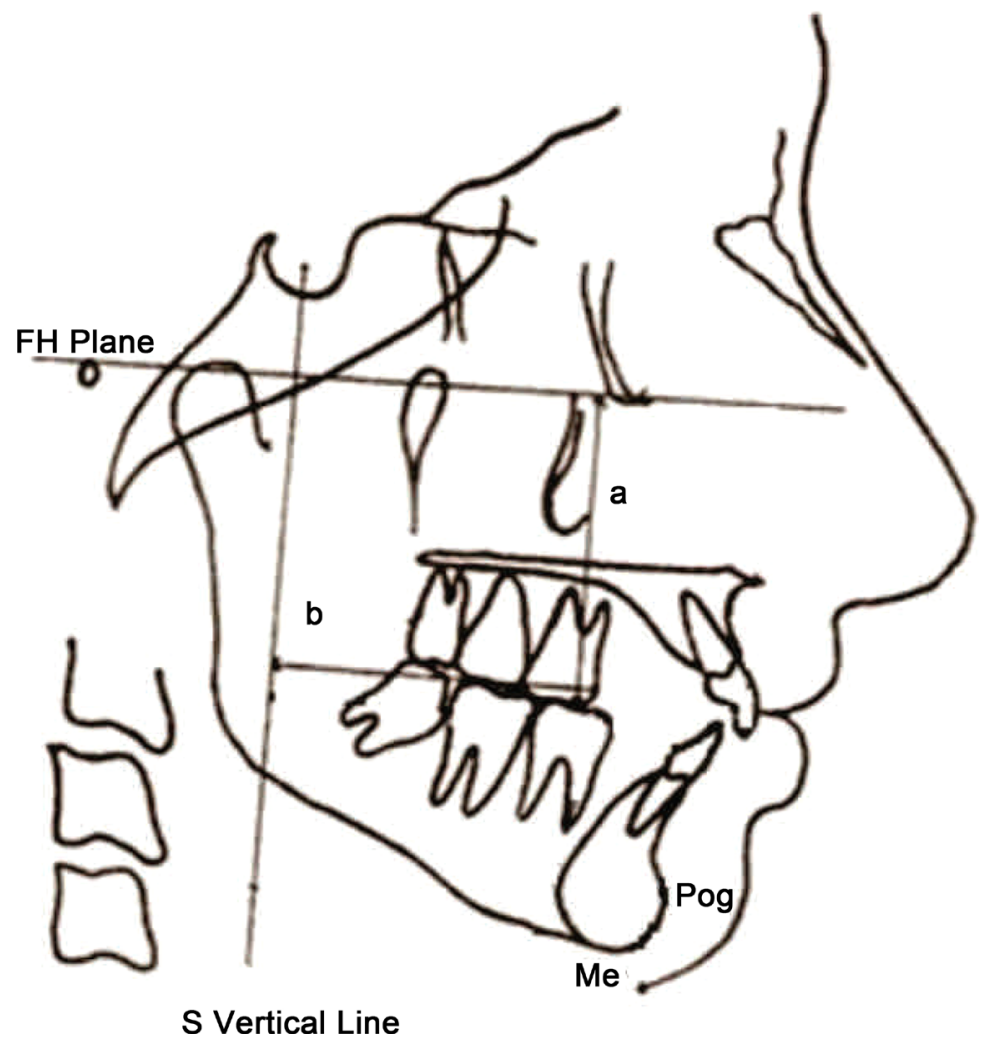

Figure 2. Cephalometric Measurement. (a) FH-U6; (b) S vertical-U6. 
Table 2. Cephalometric measurement.

\begin{tabular}{cccc}
\hline No & Measurement & Avarage & SD \\
\hline 1 & SNA $\left(^{\circ}\right)$ & 83.34 & 4.34 \\
2 & SNB $\left(^{\circ}\right)$ & 77.60 & 3.61 \\
3 & $\operatorname{ANB}\left({ }^{\circ}\right)$ & 5.80 & 1.94 \\
4 & Mandibular plane $\left(^{\circ}\right)$ & 31.63 & 6.8 \\
\hline
\end{tabular}

Table 3. Cephalometric measurement of FH-U6 and Horizontal Distance of S vertical-U6 (before and after treatment).

\begin{tabular}{cccccc}
\hline \multirow{2}{*}{ Parameter } & \multicolumn{5}{c}{$\mathbf{n}=\mathbf{2 5}$} \\
\cline { 2 - 6 } & Before & After & difference & SD & P value \\
\hline FH-U6 $(\mathrm{mm})$ & 31.63 & 32.21 & 0.58 & 2.97 & 0.061 \\
S vertical-U6 $(\mathrm{mm})$ & 45.48 & 46.33 & 0.85 & 4.48 & 0.574 \\
\hline
\end{tabular}

Significant $(P<0.05)$, Non Significant $(\mathrm{p}>0.05)$.

(Table 2).

There were no significant differenes between the variables in before and after treatment measurements. This study proved that first maxillary molar position alteration measured with FH-U6 ( $\mathrm{p}=0.061)$ and horizontal distance of maxillary SvertikalU6 ( $\mathrm{p}=0.574)$ was statistically insignificant. $(\mathrm{p}<0.05)$ (Table 3$)$. The results of this study did not support the hypothesis that premolar extraction results in a loss of anchorage.

\section{Discussion}

The aim of this study was to obtain the amount of anchorage loss occurred in Class II division 1 malocclusion treatment with two maxillary premolar extractions by measuring the mesial drifting of the maxillary first molar.

The Samples were taken from all patients with Class II division I, which had been treated at the Orthodontic Postgraduate Programme Clinic, Orthodontics Faculty of Dentistry University of Padjadjaran. They were treated by using standard Edgewise appliances.

The main purpose of orthodontic treatment for Class II division 1 was to reduce maxillary incisors proclination. Premolar extractions were aimed at providing space to correct crowding and anterior teeth inclination. During anterior teeth retraction, anchorage control was necessary in order to achieve the treatment purpose. Orthodontic treatment with extraction was proven to cause vertical dimension alteration, therefore, the following criteria has to be paid attention in orthodontic treatment [4]: (1) Anchorage. Loss of anchorage or mesial drifting caused vertical dimension to increase [6]. Anchorage was classified into the amount of posterior teeth migration during anterior teeth retraction, included minimal anchorage, moderate, and maximum anchorage. Anchorage could be obtained from teeth, oral mucosa, mini screw, and extra oral [1] 
[7]. In minimum anchorage, space closure resulted from extractions could be obtained by mesially migrated first molar. Moderate anchorage was pictured as reciprocal movement between anterior and posterior teeth towards the extracted teeth space. Maximum anchorage could be obtained from the use of head gear extra oral anchorage, summation of anchorage teeth, and the use of transpalatal arch [1] [8]. Maintenance of anchorage prevented temporomandibular disorder caused by vertical dimension reduction, which was in line with Newton's Third Law stating that for every action, there is an equal and opposite reaction. An instance for the latter was canine teeth that is planned to be moved distally with 100 grams of force, the reaction force would be 67 grams from the first maxillary molar, and 33 gr from the second maxillary premolar. The root area of maxillary incisive and canine was similar to the area of premolar and molar. Therefore, if the anterior teeth were moved palatally at the same time, the mesial migration of posterior teeth occurred with equal force. Undesirably mesially migrated of the anchorage teeth was described as loss of anchorage [1] [7]. The previous studies showed that first maxillary molar with maximum anchorage experienced mesial migration as much as $30 \%$ towards the extracted teeth space [9]-[12].

Median line correction must be conducted at the beginning of treatment, therefore, force was equally received on both left and right side. Asymmetrical force caused unilateral vertical force, causing asymmetrical dental arch and asymmetrical loss of anchorage causing vertical dimension alteration [8]. Attention on vertical force was important in order to control vertical dimension during space closure. Undesirable extrusion force at posterior teeth caused anterior face height to increase [8].

This study involved samples with second molar reinforced anchorage. Second molar involvement in increasing anchorage was a common simple anchorage system. This firm anchorage prevented the first molar from drifting. However, some studies suggested that second molar reinforced anchorage might be ineffective during enmass anterior teeth retraction in Class II division 1 treatment [10] [12] [13].

Whether premolar extractions caused loss of anchorage was still in debate. Loss of anchorage was suspected to occur due to incorrect treatment plan, inaccurate anchorage preparation, excessive force, and inappropriate mechanotherapy during treatment. Methods use to prevent loss of anchorage included the use of anchorage savers such as transpalatal arches, lingual arches, Nance palatal arches; the use of optimum force, delayed extraction, utilizing muscular forces, usage of differential force and reinforcement of anchorage [1] [3].The use of low force was an appropriate choice for anterior retraction to prevent loss of anchorage causing vertical dimension reduction [3].

Loss of anchorage was characterized with maxillary molar drifting towards mesial direction which vertically measured with FH-U6 measurement and horizontally measured with S vertical-U6. This study showed an alteration of FH-U6 as much as $0.58 \mathrm{~mm}$ before and after treatment, however it was statistically insignificant $(p=0.061)$. Similar result was obtained in horizontal $\mathrm{S}$ vertical-U6 distance that showed horizontal deviation as much as $0.85 \mathrm{~mm}$, which was also statistically insignificant $(\mathrm{p}=0.574)$, therefore, first maxillary molar alteration towards the mesial was subsided (Table 3 ). 
Absence anchorage loss in all cases taken as samples was due to the appropriately used of second molar reinforced anchorage resulting in the insignificant mesial drift of first maxillary molar.

\section{Conclusion}

According to the results of the present study, it was observed that: The first maxillary molar position was insignificantly altered in Class II division 1 treatment with two maxillary premolar extractions either vertically or horizontally, so there is no anchorage loss in this case.

\section{References}

[1] Proffit, W.R., Henry, W.F., David, M.S. and James, L.A. (2013) Contemporary Orthodontics. 5th Edition. Elsevier, St Louis, 2-5, 295-299.

[2] Kuhlberg, A.J. (2001) Step in Orthodontics Treatment. In: Bishara, S.E., Ed., Textbook of Orthoodntics, W.B. Saunders Company, Philadelphia, 239-242.

[3] Premkumar, S. (2008) Biomechanics of Tooth Movement in Prep Manual for Undergraduates Orthodontics. Elsevier, New Delhi, 263-271.

[4] Sivakumar, A. and Ashima, V. (2008) Cephalometric Assessment of Dentofacial Vertical Changes in Class I Subject Treated with and without Extraction. American Journal of Orthodontics and Dentofacial Orthopedics, 133, 869-75. http://dx.doi.org/10.1016/j.ajodo.2006.05.041

[5] Rakosi, T. (1982) An Atlas and Manual of Cephalometric Radiography. Wolfe Medical Publications, Munich, 54-58.

[6] Nanda, R., Andrew, K. and Flavio, U. (2005) Biomechanics Basis of Extraction Space Closure. In: Nanda, R., Ed., Biomechanics and Esthetic Strategies in Clinical Orthodontics, Elsevier Inc., Missouri, 194-196. http://dx.doi.org/10.1016/B978-0-7216-0196-0.50015-1

[7] Harry, D.R. and Sandy, J. (2004) Anchorage Control and Distal Movement. British Dental Journal, 196, 255-263. http://dx.doi.org/10.1038/sj.bdj.4811031

[8] Nelson, Z.L. and Moon (2007) Craniofacial Growth, the Cellular Basis of Tooth Movement and Anchorage. In: Mitchell, L., Ed., An Introduction to Orthodontics, 3th Edition, Oxford University Press, New York, 45-47.

[9] Kim, T.K., Kim, J.T., Mah, J., Yang, W.S. and Back, S.H. (2005) Fisrt or Second Premolar Extraction Effect on Facial Vertical Dimension. Angle Orthodontist, 75, 177-182.

[10] Kocadereli, I. (1999) The Effect of First Premolar Extraction on Vertical Dimension. American Journal of Orthodontics and Dentofacial Orthopedics, 116, 41-45. http://dx.doi.org/10.1016/S0889-5406(99)70301-X

[11] Upadhyay, M., Yadav, S. and Patil, S. (2008) Mini Implant Anchorage for Enmassa Retraction of Maxillary Anterior Teeth: A Clinical Cephalmetric Study. American Journal of Orthodontics and Dentofacial Orthopedics, 17, 266-269.

[12] Ibrahim, G. (2015) Comparison of the Amount of Anchorage Loss of the Molars with and without the Use of Implant Anchorage during Anterior Segment Retraction Combined with Alveolar Corticotomies. Journal of Dental Health, Oral Disorders and Therapy, 2, 00067.

[13] Londhe, S.M., Kumar, P., Mitra, R., Kotwal, A. and S.M. (2010) Efficacy of Second Molar to Achieve Anchorage Control in Maximum Anchorage Cases. MJAFI, 66, 220-224. 
Submit or recommend next manuscript to OALib Journal and we will provide best service for you:

- Publication frequency: Monthly

- 9 subject areas of science, technology and medicine

- Fair and rigorous peer-review system

- Fast publication process

- Article promotion in various social networking sites (LinkedIn, Facebook, Twitter, etc.)

- Maximum dissemination of your research work

Submit Your Paper Online: Click Here to Submit

Or Contact service@oalib.com 